DANILO DE SALAZAR

\title{
REALIZAREA SINESTEZIEI PE PLAN PARADIGMATIC
}

\section{Introducere}

În studiul ei din 1995, La sinestesia. Storia e analisi del concetto, Paola Paissa își focalizează atenția asupra caracterului sintagmatic al sinesteziei, considerându-1 drept unul dintre elementele distinctive care deosebesc configuraţia intersenzorială de metaforă:

„Dacă, după nexul analogic, se poate determina caracterul in praesentia sau in absentia al predicației metaforice, elementul constitutiv al sinesteziei este, dimpotrivă, întotdeauna predicația in praesentia. Față de metaforă, care se desfăşoară de obicei pe plan paradigmatic, sinestezia se construiește după o schemă de tip serial, cumulativ, configurându-se deci ca o figură sintagmatică. [...] Dacă în ceea ce privește metafora, condiția minimală a existenței este aceea de a fi binară in absentia, în cazul sinesteziei ea este de a fi binară in praesentia" (Paissa 1995, p. 92) ${ }^{1}$.

Aserțiunea lingvistei de la Universitatea din Torino este rezultatul unui demers teoretic care impune reconsiderarea raportului dintre sinestezie și tropii analogici și cei non-analogici, o relație care pentru prea mult timp a fost interpretată în termeni de subordonare a unei configurații față de cealaltă (ibidem, p. 77). Depășirea acestei perspective de subordonare este determinată de faptul că dezvoltarea analitică a unei sinestezii poate presupune pe plan conceptual o analogie (deci un raport de tip metaforic) sau o contiguitate, adică un raport de tip metonimic. Asupra acestui ultim tip de proces ne vom concentra, luând în considerare posibilitatea ca sinestezia să se manifeste printr-o structură binară in absentia. Ipoteza noastră se bazează pe rezultatele obținute din cercetarea efectuată asupra operelor unor autori români moderni (este vorba de sinestezia literară) unde, bineînțeles, marea majoritate a ocurențelor sinestezice înregistrate sunt de tip sintagmatic, ceea ce confirmă valabilitatea generală a teoriei.

Fiind metonimia procesul retoric implicat, este necesar să descriem preliminar relația dintre aceasta și sinestezia pe baza celor mai recente observații științifice ${ }^{2}$ :

\footnotetext{
1 „A prescindere dal nesso analogico che può fondare in absentia o in praesentia la predicazione metaforica, l'elemento costitutivo della sinestesia è perciò, a nostro avviso, sempre e comunque la predicazione in praesentia. Rispetto alla metafora, che è tradizionalmente ricondotta all'asse paradigmatico, la sinestesia si costituisce quindi secondo uno schema seriale, accumulativo, ed è pertanto figura di tipo sintagmatico. [...] Mentre per la metafora la condizione minimale di esistenza è quella di essere binaria in absentia, per la sinestesia è quella di essere binaria in praesentia" (Paissa 1995, p. 92).

2 Printre cele mai recente cercetări asupra sinesteziei, semnalăm și interesantele studii semnate de Francesca Strik Lievers (vezi Strik Lievers 2017, Strik Lievers 2018 și Strik Lievers, Huang, Xiong 2021).
} 
ne referim în mod special la volumul publicat în 2017 de lingvistul italian Michele Prandi, Conceptual Conflicts in Metaphors and Figurative Language, unde raportul dintre cele două procese este interpretat, pe plan conceptual, în termeni de concurență.

\section{Opțiunile interpretative}

După părerea lui Prandi, o imagine de tip intersenzorial poate fi interpretată ca o sinestezie propriu-zisă sau pe baza unui mecanism metonimic, cele două procese retorice fiind între ele incompatibile. Autorul propune ca exemplu următoarea frază a lui Guy de Maupassant, "And so they remained, both of them, motionless and without speaking, in the black silence"3, explicând că:

"The expression [...] is open toward both synesthesia - silence is black - and metonymy: the noun silence refers to the stable where the characters are. If metonymy is chosen, the stable becomes the relevant textual topic and attracts the adjective black into a consistent relation at the expense of synesthesia: the stable is both dark and silent" (Prandi 2017, p. 111).

Odată ce este definită izotopia contextuală faţă de care enunțul își manifestă incoerența semantică, se poate releva eventuala existență a unui conflict conceptual pe plan sintagmatic și, prin urmare, genul de „soluție" pe care contextul respectiv o sugerează, adică o interpretare de tip sinestezic sau metonimic a imaginii. Posibilitatea de a se orienta spre unul sau celălalt proces sporește ceea ce autorul denumește „densitate semantică” a unui enunț ("The competing options are not taking as alternative but tend to cumulate into semantic density and dynamic tension" ibidem, p. 111), intensificată și de așa-zisa modificare oblică, ulterioară opțiune interpretativă, la rândul ei „,concurentă” cu sinestezia și cu metonimia: “As independent structures, synesthesia and metonymy typically compete in texts, both with each other and with oblique modification" (ibidem).

Concentrându-ne atenția asupra procesului de modificare oblică care interesează substantivul implicat în joncțiunea atributivă, vom ajunge la descrierea unei inedite configurații sinestezice - structura binară in absentia - pentru a cărei realizare este necesar să se opereze metonimic asupra numelui, ceea ce ar permite, cel puțin în acest caz specific, ca raportul dintre cele două procese să nu fie citit în termeni de „,concurență", ci relevând în el un caracter de complementaritate. Înainte de a proceda cu descrierea acestei configurații, se impune o definire preliminară a metonimiei, a cărei încadrare retorică s-a dovedit în ultimul secol destul de complexă din punct de vedere teoretic. De fapt, metonimia a fost prea des analizată doar în raport cu metafora și cu sinecdoca, în cel din urmă caz resimțind de multe ori o completă asimilare în interiorul aceluiași perimetru de existență. Această abordare analitică a

\footnotetext{
3 În cartea lui Michele Prandi găsim traducerea în limba engleză a textului francez original: „Ils restaient là tous deux, immobiles, muets dans le silence noir" (din Histoire d'une fille de ferme de Guy de Maupassant). Exemplul este reluat și în studiul asupra sinesteziei condus de Paola Paissa (Paissa 1995, p. 86), şi în cadrul analizei retoric-traductologice propuse de Annafrancesca Naccarato (Naccarato 2012, p. 64).
} 
figurii nu este dovada unei subestimări a propriei ei valori în câmp retoric - în ceea ce privește frecvența de uz și specificitatea relațiilor semantice pe care ea este în stare să le realizeze -, ci se naște dintr-o exigență analitică mai profundă, legată de categorii conceptuale mai ample și fundamentale ca analogia și contiguitatea pe bază contextuală.

\section{O scurtă încadrare retorică a metonimiei}

Drept dovadă a interferenței dintre metonimie și metaforă propunem următoarea afirmație a lui Albert Henry: „Souvenons-nous qu'on a dit et répété: pas de métaphore qui ne soit toujours plus ou moins métonimyque; pas de métonymie qui ne soit quelque peu métaphorique" (Henry 1971, p. 50). Genericitatea acestei aserțiuni este semnul unei tendințe difuze - nu chiar poziția lui Henry - de a considera mecanismul metaforic drept cel fundamental în câmp retoric, ca un fel de macrocategorie în care se înscriu toate celelalte figuri de semnificaţie, cu riscul ca extinderea conceptului însuși de metaforă să reducă specificitățile celorlalte configurații, recunoscând în ele doar un caracter superficial, de natură strict expresivă. Abordarea răspunde principiului de deviere, de ecart, în detrimentul căruia a intervenit modelul interacționist, cu focalizările lui necesare asupra determinantelor contextuale și considerările privitoare la nivelurile de realitate în interiorul și în afara textului. Recurgerea la ideea de izotopie permite, de fapt, a acționa pe plan conceptual, relevând gradul mai mare sau mai mic de corespondență a unui element față de logicile pe care se mișcă întregul text, nivelul de coerență sau fractura pe care el o determină în înțelegerea complexă. Pe aceste baze vom avea posibilitatea de a distinge între un mecanism retoric și celălalt, fiindcă cel dintâi (metonimia) asigură niveluri de contiguitate logică față de izotopia generală, în timp ce al doilea (metafora) produce o ruptură imediat recognoscibilă în dimensiunea de realitate a textului în care un anumit element „străin” este introdus:

„Le lexème formant métonymie ou synecdoque n'est pas senti, sauf dans de très rares cas particuliers, comme étranger à l'isotopie. La métaphore au contraire, à condition que ce soit une métaphore vivante et faisant image, apparaît, immédiatement comme étrangère à l'isotopie du texte où elle est insérée" (Le Guern 1973, p. 16).

O problemă ulterioară se naște însă din necesara deosebire față de cealaltă așazisă figură de contiguitate, adică sinecdoca. „On accorde que la distinction faite entre la métonymie et la synecdoque n'est qu'un jeu futile”: comentariul „cu scop didactic" din $1957^{4}$ este reluat critic de Albert Henry în capitolul dedicat descrierii naturii și a mecanismului de creare a metonimiei (Henry 1971: 18). Nu împărtăşim afirmația, dar recunoaștem în peremptorietatea ei expresia drastică a unei chestiuni

\footnotetext{
${ }^{4}$ Este vorba de un comentariu apărut în Programme et Instructions métodologiques. Commentaires (1957) pentru învătământul din Belgia, reluat de A. Willelm în Principes de rhétorique, citat în Henry 1971, p. 18.
} 
mai vechi, cu caracter nu doar strict taxonomic, care revelă incertitudinea și labilitatea hotarului dintre cele două figuri:

„Les dictionnaires et les traités de rhétorique nous laissent en pleine confusion quant à la nature véritable de la métonymie et de la synecdoque. Il n'est pas question, pour le moment, des difficultés, réelles, de l'analyse dans certains cas concrets, où l'on peut hésiter entre deux principes d'explication [...]. Non, les difficultés sont surtout d'ordre théorique. Aussi, ce qui est métonymie pour les uns est-il parfois synecdoque pour d'autres" (Henry 1971, p. 17).

Henry încearcă să clarifice chestiunea, propunând reluarea și dezvoltarea deosebirii operate de Gaston Esnault (vezi Esnault 1925) dintre notiunea de „,comprehensiune”, care stă la baza metonimiei, și cea de „extensiune”, referitoare la sinecdocă $\breve{a}^{5}$, în funcție de tipul de mutare a naturii logicii pe care cele două figuri o presupun: „La synecdoque opère un changement dans l'extension logique du mot; elle substitue à un mot un terme d'extension différente. La métonymie opérerait un changement dans la comprehénsion logique d'un mot; elle substitue à un mot un terme de compréhension différente" (Henry 1971, p. 19).

Suntem de acord, totuși, cu Pier Marco Bertinetto (Bertinetto 1975), care, în introducerea ediției italiene a textului, manifestă o anumită perplexitate față de valabilitatea celor două noțiuni identificate de Esnault, comprehensiune și extensiune, care sunt „dialectic legate” - solidare și chiar ,invers proporționale”, după Henry $^{6}$ - și din cauza asta probabil nu pot fi considerate drept criterii de referință pentru a opera o distincție între cele două figuri ${ }^{7}$.

Filologul belgian subliniază faptul că ambele mecanisme activează procese care se desfășoară pe aceeași logică directoare (,,Bois ton bourgogne sera une métonymie, si le vin dont il est question a été élevé en Bourgogne, mais sera une synecdoque, si le verre contient un rouge quelconque, fabriqué n'importe où" - Henry 1971, p. 22), recunoscând încă o dată analiza contextuală drept soluția posibilă pentru a ieși din impas: „Dans de nombreux cas, c'est l'analyse du contexte ou de la situation qui permet seule de trancher" (ibidem). Câteva rânduri mai jos autorul atinge miezul chestiunii, mutându-se definitiv pe plan conceptual, explicitând caracterul de fond general care leagă

\footnotetext{
5 „Il est étonnant qu'on n'ait pas accordé plus d'attention aux vues théoriques qu'il [Gaston Esnault] a exposées dans l'introduction à sa thèse sur les Métaphores occidentales. Voici la distinction décisive qu'il a établie et qui restera le fondement de nos considérations. À la base de la métonymie, se trouve la notion de compréhension; à la base de la synecdoque, celle d'extension" (ibidem).

6 „Compréhension et extension sont solidaires et même en raison inverse l'une de l'autre: si l'extension croît, la compréhension décroît, et inversement. La classification des sciences naturelles est une sorte de projection taxinomique de ce mouvement. Dans la série rouge-gorge, passereau, oiseau, la compréhension respective des termes est en ordre décroissant et leur extension respective en ordre croissant" (ibidem).

${ }^{7}$ „Nu mai puțin nedumeriți ne lasă afirmațiile lui Henry, reluate de la G. Esnault, conform cărora metonimia se bazează pe modificarea comprehensiunii logice a unui cuvânt, în timp ce sinecdoca se bazează pe modificarea extensiunii logice. Nu este clar cum aceste două concepte, dialectic legate, pot servi pentru realizarea unei deosebiri de acest tip, considerând că orice modificare a extensiunii produce o inevitabilă modificare a comprehensiunii, și invers” (Bertinetto 1975, p. IX).
} 
cele două figuri, adică contiguitatea, pornind de la care se poate opera o distincție după tipul de relație la care se referă definițiile obișnuite ale metonimiei și ale sinecdocei: contiguitate spațială, temporală și cauzală pentru cea dintâi; mai mare sau mai mică extensiune - raport parte/întreg sau gen/specie - pentru cea de-a doua:

„Métonymie et synecdoque ne se réfèrent qu'indirectement aux séries phénoménales, et ce n'est pas exactement de compréhension logique et d'extension logique qu'il faut parler, mais, plus largement, de compréhension psychologique et d'extension psychologique. Métonymie et synecdoque exploitent une association entre deux représentations contiguës; elles respectent une certaine structure conceptuelle, mais l'ordre des phénomènes seulement d'une manière indirecte. Essentiellement; contiguïté conceptuelle" (ibidem).

Principiul contextual va juca un rol central în argumentarea propusă de autor în cel de-al doilea capitol, unde se definește statutul figurilor de contiguitate: „Le sens de l'expression figurée ne se révélera nettement que grâce au contexte approprié ou à la situation [...]. Quand il s'agit d'œuvres littéraires surtout, il faut bien se souvenir que les effets stylistiques dégagés sont fonction des réalités évoquées, de la situation et du contexte verbal" (ibidem, p. 30-31).

\title{
4. Interpretarea metonimică a unor configurații intersenzoriale
}

Odată ce a fost definit câmpul de existență a metonimiei, vom proceda cu analiza raporturilor pe care ea le întreține cu sinestezia, pornind de la unele configurații textuale de tip literar în care relația se manifestă în mod mai mult sau mai puțin explicit. Dacă metafora reprezintă una din posibile dezvoltări interpretative ale sinesteziei, reflecțiile asupra subiectului propuse de Paola Paissa ne îndeamnă să considerăm și posibilitatea unei evoluări metonimice a enunțului (Paissa 1995, p. 85-91) în care sunt implicate două elemente din domenii senzoriale diferite. Caracterul metonimic al sinesteziei este destul de frecvent, deși pentru a-l identifica nu este suficientă analiza enunţului ca atare, revelându-se necesară și observarea contextului, așa cum se poate nota în versurile următoare:

\author{
„Şi-un imn solemn de mute, reci columne, \\ în corul alb al nemișcării lor, \\ ne-a închinat anticul port surpat". \\ (Ion Vinea, Comemorare, vv. 32-33 - Vinea 2016, p. 52).
}

Versurile lui Ion Vinea oferă imagini atât de sugestive cât și de complexe în construcția lor retorică. În pasajul citat sinestezia nu se configurează ca o relație binară, deoarece elementele implicate își manifestă incompatibilitatea senzorială în mod combinat: „columnele” din primul vers sunt definite „reci” și, mai ales, „mute”, producând nu doar o îmbinare sinestezică prin acostarea unei senzaţii tactile cu una auditivă, ci activând o relație de tip oximoronic ${ }^{8}$ cu substantivul „imn”, deși adjectivul (mute) nu se referă la el în mod direct. În cazul de față, „imnul

\footnotetext{
${ }^{8}$ Oximoronul posedă și capacitatea de a evidenția conflictul conceptual în interiorul unui enunț, fiindcă nivelul de incompatibilitate semantică ajunge la cel mai înalt grad, exaltând în același timp sugestivitatea imaginii respective.
} 
solemn" reprezintă focus-ul metaforic (vezi Black 1962, p. 25-47), în timp ce pentru a depista contiguitatea dintre sinesteziile conţinute în versuri - „mute...columne” și „corul... alb" - atenția trebuie focalizată asupra specificei caracterizări a diferitelor sfere senzoriale care compun rama contextuală, unde relevăm: absența sunetelor, datorită adjectivului „mute”; absența căldurii, prin adjectivul „reci”; prezența albului, definit de obicei ,acromatic”; în fine, deși nu este imediat asimilabilă unui anumit domeniu senzorial, cităm și absența mișcării. În această perspectivă și adjectivul „mute” își redobândește coerența față de contextul în care se află, și sinestezia, prin urmare, își găsește o posibilă soluție interpretativă metonimică, dată fiind incompatibilitatea semantică produsă de prezența unui „,imn” a cărui solemnitate este de căutat chiar în tăcerea adâncă care caracterizează imaginea.

Acest tip de descriere nu este inedit la Vinea: în Vid - „Chem umbre, voci, dintre fațade mute" (Vinea 2016, p. 81) - găsim de fapt „fațadele mute”, unde adjectivul se încadrează în senzația de tăcere și singurătate generală a poemului; avem și ,palidul imn” din versurile dedicate lui Aetius, unde adjectivul nu poate fi analizat doar în accepția lui vizuală, ca o pierdere de intensitate cromatică, fiindcă el servește pentru descrierea sentimentului de reverență față de gloria generalului:

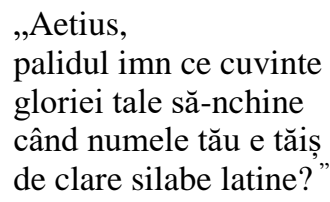

(Ion Vinea, Aetius, vv. 7-11 - Vinea 2016, p. 86).

După cum am relevat analizând exemplele propuse, putem observa că desfășurarea metonimică reprezintă una dintre opțiunile valabile pentru a interpreta sinestezia, înțeleasă ca proces retoric care se naște din ,interacțiunea dintre două sau mai multe elemente din text care își manifestă incompatibilitatea semantică din punct de vedere senzorial” (De Salazar 2017, p. 102). In funcție de relaţia dintre elementele implicate în sinestezie se stabilește dacă este vorba de o desfășurare metaforică sau de una metonimică. Alegerea nu poate fi făcută decât în urma unei reflecții asupra contextului, pentru a verifica eventuala ruptură a izotopiei: în exemplele citate, contextul ne îndeamnă să tindem spre o interpretare de tip metonimic, o operațiune care, într-o anumită măsură, restabilește coerența semantică a enunțului, rezolvând conflictul conceptual declanșat pe plan sintagmatic.

În cartea lui din 1992, Grammaire philosophique des tropes, Michele Prandi descrie structurile retorice prin care se poate manifesta conflictul conceptual, analizând în mod detaliat și potențialitățile interacționale ale diferitelor părți ale discursului și tipologiile de relație pe care ele sunt în stare să le activeze. Paragraful dedicat distribuirii tropilor în interiorul unei structuri predicative (Prandi 1992, p. 86102) se încheie cu analiza comportamentului semantic al adjectivului (ibidem, p. 96), care, în calitate de modificator, își declanșează potențialul figurativ în raport cu substantivul: „C'est donc à l'intérieur de l'expression nominale que nous nous proposons d'explorer le potentiel figural de l'adjectif. Syntaxiquement, un modificateur 
dépend d'un terme de rang supérieur, qu'il modifie: l'adjectif dépend d'un nom" (ibidem). Dar modificarea produsă de către adjectiv poate avea două aspecte diferite, adică el poate acționa în mod mai mult sau mai puțin direct asupra substantivului la care se referă. În această privință, Prandi vorbește de „modificare directă” și de „modificare oblică”:

„Agissant directement sur le nom modifié comme une sorte de prédicat implicite, le modificateur restreindrait son pouvoir de désignation, rendant son contenu plus précis. [...] L'adjectif dispose en effet d'une ressource systématique que la définition traditionelle ignore: la capacité de contourner sur le plan sémantique la relation établie sur le plan syntaxique, réalisant une forme oblique de modification" (ibidem, p. 96).

În cea dintâi categorie, cea a modificării directe, se înscriu oximoronul și metafora adjectivală: oximoronul este definit drept ,trop al contradicției directe", exprimă în relația dintre conținuturile explicite în interiorul enunțului, în timp ce metafora adjectivală implică un referent virtual al numelui, producând o contradicție la nivel de categorii ontologice. Exemplul propus de Prandi este canuto pomeriggio (,după-amiază căruntă”), unde, prin adjectiv, i se atribuie după-amiezii însuşiri omenești: „Le référent du nom modifié est censé posséder, au sens métaphorique, la qualité que le modificateur lui attribue. L'après-midi de notre exemple est, métaphoriquement, aussi chenu, qu'un vieillard l'est littéralement" (ibidem, p. 97).

Trecând la modificarea oblică activată de o metaforă de tip nume-adjectiv, lingvistul propune expresia următoare, un passo sorridente („un pas surâzător”) unde modificatorul își găsește referentul în afara enunțului, ceea ce produce alunecarea liniei directoare a relației pe plan paradigmatic: „Au lieu d'atteindre par une ligne droite son partenaire syntaxique, le modificateur répond par un parcours diagonal à l'appel d'un double solidaire: un passo sorridente est le pas d'une personne souriante" (ibidem, p. 97). Ceea ce se creează este deci un raport oblic care exploatează mecanismul metonimic activ asupra numelui (pas > persoană), necesar pentru a restabili coerența semantică a enunțului:

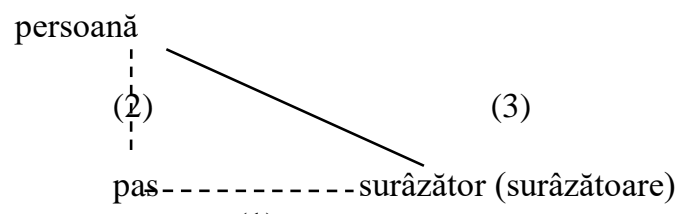

(1)

Fig. 1, unde:

(1) linia întreruptă indică raportul de incompatibilitate semantică in praesentia;

(2) linia întreruptă pentru a desemna procesul metonimic activat asupra substantivului;

\footnotetext{
9 „Au lieu d'expliciter une propriété inhérente des référents virtuels du nom, ou de leur attribuer une propriété accidentelle compatible, l'oxymore contredit explicitement l'une de leurs propriétés inhérentes" (ibidem, p. 97).
} 
(3) linia continuă care restabilește coerența enunțului.

Același mecanism de dezambiguizare semantică s-ar putea folosi și în cazul sinesteziei: luăm în considerare expresia „umbra rece”, extrasă din poemul Cântece simple: Mărior, al lui B. Fundoianu, în care citim:

„Știu, o să vii în seară ca de obicei, s-aduci pe tine umbra rece a frunzelor de nuci."

(Cântece simple: Mărior - VI, vv. 5-6 - Fundoianu 2011, p. 160)

Aici intersenzorialitatea determinată de joncțiunea adjectivală în care apare un substantiv de tip vizual („umbră”) și un adjectiv din domeniul pipăitului („rece”) nu produce nicio stridență semantică, putându-se rezolva printr-o metonimie de tip cauză-efect: imaginea evocă de fapt senzația de răcoare percepută stând la umbra unui nuc. Determinantele contextuale oferă posibilitatea de a interpreta relația pe bază metonimică, restituind logica enunțului dintr-o izotopie realistă a imaginii. La fel se întâmplă în pasajul următor din Psalmul lui Adam, tot al lui B. Fundoianu, unde efectul sinestezic este redat printr-o configurație de tip prepozițional:

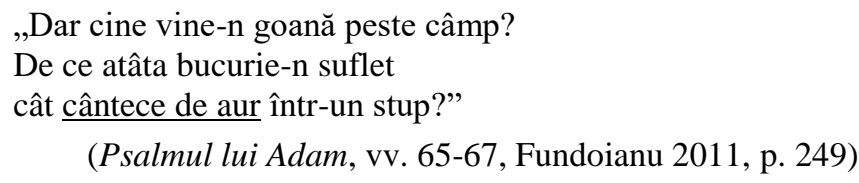

În expresia „cântece de aur”, substantivul este o eufemizare a sunetului produs de albine, în timp ce, folosind atributul ,de aur”, poetul reușește într-o evocare poetică a insectelor respective printr-o eufemizare ulterioară care se referă la culoarea lor. Deși imaginea merită o aprofundare analitică care să țină cont de valențele simbolice care leagă - din punctul de vedere al imaginarului - mierea și aurul, sufletul și stupul, identificarea albinelor drept referentul virtual al „cântecelor” din versuri este destul de imediată pentru cititor, conflictul intersenzorial inițial găsind o soluție reducționistă în expresia „cântecele albinelor”. Din exemplele citate se poate nota că opțiunea metonimică, rezolvând conflictul conceptual, anulează caracterul intersenzorial pe care expresia îl manifestă la nivel textual, deci de fapt anulează sinestezia. Înțelegem asta când vorbim de concurența dintre sinestezie și metonimie, teza respectivă fiind a lui Michele Prandi: „Synesthesia presupposes the stability of the relation between the adjective and the head noun; since it activates a shift in the reference of the latter, metonymy dissolves the relation itself" (Prandi 2017, p. 111). Ca și în cazurile citate, coerența semantică se dobândește doar apelându-se la un referent extern, din afara enunţului, evocat în text printr-o strategie metonimică.

\section{Dezvoltarea sinesteziei pe plan paradigmatic}

Ipoteza noastră prevede însă posibilitatea de a răsturna perspectiva analitică: deși sunt foarte rare, există cazuri în care metonimia nu oferă nicio soluție interpretativă pentru o sinestezie, ci chiar prin metonimie se realizează o relație inter- 
senzorială care nu apare în enunţ, revelându-se drept procesul indispensabil pentru crearea și înțelegerea respectivei imagini literare. Sinestezia de acest tip are o structură binară in absentia, adică se produce în momentul în care se rupe coerența semantică pe care un enunț o manifestă pe plan sintagmatic. Bineînțeles, ca și în cazul metaforei, această operațiune este rezultatul unei opțiuni interpretative preliminare care ține cont de contextul în care apare expresia sinestezică. Exemplul următor este extras din celebrul poem Dans al lui Nicolae Labiș:

„Sângeră vioara neagră-ntre oglinzi”

(Nicolae Labiș, Dans, v. 5 - Labiș 2001, p. 113)

Versul citat are un caracter metaforic explicit și, prin tonul lui melancolic și trist, se încadrează perfect în poemul din care este extras, care nu întâmplător se încheie cu cuvântul „remușcare”. Izolând sintagma „,vioara neagră”, vom remarca faptul că între cele două elemente care o compun nu există nicio incompatibilitate, astfel încât am putea observa că adjectivul „neagră” intervine în mod direct ca modificator asupra substantivului „vioară”, instaurând cu el o relație orizontală, coerentă din punct de vedere semantic. Deși ni se pare legitimă opțiunea pentru o lectură realistă a imaginii, după care adjectivul n-ar fi altceva decât o specificare cromatică a instrumentului muzical, credem că nu doar contextul, ci și titlul poemului impun o operație de tip metonimic asupra numelui, identificând în cuvântul „vioară" trimiterea la melodia pe care ea o produce: prin urmare, ceea ce vom obține va fi chiar o sinestezie de tip auz-văz, adică melodie neagră. Notăm că, spre deosebire de ce am observat mai sus cu expresia un passo sorridente (,un pas surâzător"), în cazul de față referentul virtual (melodie) nu poate fi considerat un referent „solidar” pentru adjectiv (neagră), între ele nefiind nicio compatibilitate semantică dintr-o izotopie realistă a imaginii. Reluând reprezentarea grafică pe care am folosit-o mai sus, în Fig. 2 vom observa că linia continuă (cea care reprezintă raportul coerent din punct de vedere semantic) se află acum pe plan orizontal, descriind relația care se manifestă la nivel sintagmatic, în timp ce valoarea figurativă a imaginii va fi exprimată printr-o metonimie, tot asupra substantivului (2), și printr-o sinestezie reprezentată de un segment oblic (3):

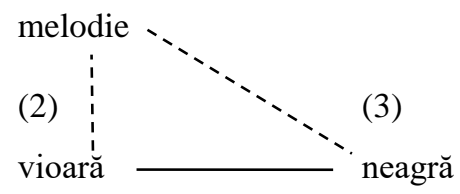

(1)

Fig. 2, unde:

(1) linia continuă care reprezintă raportul coerent din punct de vedere semantic (in praesentia);

(2) linia întreruptă pentru a desemna procesul metonimic activat asupra substantivului;

(3) linia întreruptă care indică raportul sinestezic in absentia. 
Pornind de la o configurație nume-adjectiv care nu manifestă incompatibilitate semantică pe plan sintagmatic, putem obține deci o sinestezie binară în care un element este adjectivul (prezent în enunț) în timp ce cel de-al doilea element va fi un referent virtual (in absentia) obținut din exigențe interpretative activând o metonimie asupra numelui ${ }^{10}$.

Teoria formulată de Paola Paissa, după care condiția minimală de existență a sinesteziei este cea de a fi o relație binară in praesentia, deși este valabilă în majoritatea ocurențelor de tip literar, în acest caz este dezmințită de faptul că un termen al interacțiunii este prezent în enunţ, în timp ce „partenerul” lui semantic nu este cel care apare în expresia textuală, ci este un subiect virtual identificat pe axa paradigmatică. Ceea ce rezultă extrem de interesant este și faptul că aici metonimia nu se configurează drept procesul interpretativ pentru a rezolva conflictul semantic declanșat de sinestezie, ci este procesul germinativ al sinesteziei: prin metonimie se generează o interacțiune sinestezică care este intuită de subiectul interpretant dar care nu se manifestă pe plan sintagmatic. Intenția noastră este aceea de a demonstra că raportul dintre metonimie și sinestezie nu este mereu unul de competiție sau de concurență pe plan conceptual, ci se poate transforma, depăşind granițele sintagmatice ale enunțului, într-o dinamică de complementaritate: în primele cazuri analizate metonimia anula de fapt o sinestezie care exista pe planul imanent al textului, în timp ce în ultimul exemplu este chiar o metonimie cea care creează o sinestezie care nu se manifesta la suprafața textului lui Labiș.

Forma literară - mai ales poezia - reprezintă un teren deosebit de fertil pentru experimentarea retorică, unde și sinestezia reușește să depășească limitele planului sintagmatic, declanşând, prin participarea subiectului interpretant, propriul ei potențial la nivel imaginativ.

\section{ABREVIERI BIBLIOGRAFICE}

Black 1962 = Max Black, Models and Metaphors, Ithaca, Cornell University Press, 1962

Bertinetto 1975 = Pier Marco Bertinetto, Introduzione, în A. Henry, Metonimia e metafora, Torino, Giulio Einaudi, 1975.

De Salazar 2017 = Danilo De Salazar, Sviluppi nello studio della sinestesia letteraria in ambito linguistico italiano e romeno, în „Analele Universității București. Limba și literatura română”, LXVI, 2017, p. 87-105.

Esnault 1925 = Gaston Esnault, L'imagination populaire, Métaphores occidentales, Paris, PUF, 1925. Fundoianu 2011 = B. Fundoianu, Opere. Vol. 1. Poezia antumă. Ediţie îngrijită de P. Daniel, G. Zarafu și M. Martin, București, Editura Art, 2011.

Henry 1971 = Albert Henry, Métonymie et métaphore, Paris, Klincksieck, 1971.

Labiș 2001 = Nicolae Labiș, Moartea căprioarei. Ediție îngrijită de Anatol și Dan Vidrașcu, București - Chișinău, Litera Internațional, 2001.

\footnotetext{
10 În exemplul citat, bineînțeles, sinestezia pe care am obținut-o impune o interpretare de tip metaforic în care trebuie să se țină cont, printre altele, de multipla valență simbolică a culorii negre.
} 
Le Guern 1973 = Michel Le Guern, Sémantique de la métaphore et de la métonymie, Paris, Larousse, 1973.

Naccarato 2012 = Annafrancesca Naccarato, Traduire l'image. L'œuvre de Gaton Bachelard en italien, Roma, Aracne, 1973.

Paissa 1995 = Paola Paissa, La Sinestesia. Storia e analisi del concetto, Brescia, La Scuola, 1995.

Prandi 1992 = Michele Prandi, Grammaire philosophique des tropes, Paris, Les Éditions de Minuit, 1992.

Prandi 2017 = Michele Prandi, Conceptual Conflicts in Metaphors and Figurative Language, New York, Routledge, 2017.

Strik Lievers 2017 = Francesca Strik Lievers, Figures and the Senses: Towards a Definition of Synaesthesia, în „Review of Cognitive Linguistics”, 2017, vol. 15, nr. 1, p. 83-101.

Strik Lievers 2018 = Francesca Strik Lievers, Synaesthesia and Other Figures. What the Senses Tell Us About Figurative Language, în Annalisa Baicchi, Rémi Digonnet, Jodi L. Sandford (eds.), Sensory Perceptions in Language, Embodiment and Epistemology. Studies in Applied Philosophy, Epistemology and Rational Ethics, Berlin, Springer, 2018, p. 193-207.

Strik Lievers, Huang, Xiong 2021 = Francesca Strik Lievers, C. R. Huang, J. Xiong, Linguistic Synaesthesia, în Wen Xu și John R. Taylor (eds.), The Routledge Handbook of Cognitive Linguistics, London - New York, Routledge Handbook, p. 372-383.

Vinea 2016 = Ion Vinea, Opere - Poezii. Ediție îngrijită de E. Zaharia Filipaș, București, Academia Română - Fundația Națională pentru Știință și Artă, 2016.

\section{THE MANIFESTATION OF SYNAESTHESIA ON THE PARADIGMATIC LEVEL}

(Abstract)

Synaesthesia is a rhetorical configuration that develops on the syntagmatic level. The Italian scholar Paola Paissa offers a definition of synaesthesia in contrast to metaphor, describing it as a figure whose minimal condition of existence is that of being binary in praesentia, a construction in which the implied elements appear within the text. In this essay we will deal with synaesthesia in the literary sphere, with the intention of demonstrating that there is a possibility that it may be manifested not entirely in the text, that is, by identifying - through a metonymic operation that insists on the noun of a binary attributive junction - a virtual referent external to the utterance.

Cuvinte-cheie: sinsestezie, metaforă, metonimie, limba română, literatura română.

Keywords: synaesthesia, metaphor, metonimy, Romanian language, Romanian literature.

Universitatà della Calabria

Reggio Calabria, Via dell'Università, 25

Italia

danilo.desalazar@unical.it 